\title{
Epidemiology and Natural History of Psoriatic Arthritis: an Update What Dermatologists Need to Know
}

\author{
R. Michelle Koolaee • Junko Takeshita • Alexis Ogdie
}

Published online: 5 January 2013

(C) Springer Science+Business Media New York 2013

\begin{abstract}
Psoriatic arthritis (PsA) is a chronic inflammatory disease that can be associated with permanent joint damage and disability. Because patients may be unaware of the association of joint disease with psoriasis, dermatologists play an important role in identifying PsA. In this review, we discuss the natural history and key features of PsA, the epidemiology and hypothesized risk factors for disease, and screening tools that can be used in the dermatology clinic to aid in identifying which patients should be referred to a rheumatologist for further assessment.
\end{abstract}

Keywords Psoriatic arthritis · Epidemiology · Psoriasis · Incidence $\cdot$ Prevalence $\cdot$ Risk factors $\cdot$ Screening tools

\section{Introduction}

Psoriatic arthritis (PsA) is a chronic inflammatory disease that can be associated with permanent joint damage and disability. Identification and appropriate treatment can dramatically improve quality of life in patients with PsA $[1,2]$.

\section{R. M. Koolaee}

Division of Rheumatology, Perelman School of Medicine

at the University of Pennsylvania, 827 Penn Tower,

34th \& Civic Center Boulevard,

Philadelphia, PA 19104, USA

e-mail: Roodabeh.Koolaee@uphs.upenn.edu

J. Takeshita

Department of Dermatology, University of Pennsylvania,

1 Convention Ave. 1468 Penn Tower,

Philadelphia, PA 19104, USA

\author{
A. Ogdie $(\square)$ \\ Division of Rheumatology, Center for Clinical Epidemiology \\ and Biostatistics, Perelman School of Medicine at the University \\ of Pennsylvania, 816 Penn Tower, 1 Convention Ave, \\ Philadelphia, PA 19104, USA \\ e-mail: alexis.ogdie@uphs.upenn.edu
}

However, PsA often can be difficult to identify. In many patients with PsA, the symptoms of arthritis do not develop until years after the onset of cutaneous psoriasis. Dermatologists play a critical role in screening for PsA, because many patients are not aware of the link between joint disease and psoriasis. In this review, we address the epidemiology, natural history, and clinical characteristics of this disease, as well as available screening tools to provide dermatologists the information needed to identify patients with PsA.

\section{Characteristics of Disease and Natural History}

\section{Clinical Features}

Psoriatic arthritis is an inflammatory arthritis involving the articular and periarticular structures and most often is associated with psoriasis. PsA was initially thought to be mild compared with rheumatoid arthritis (RA), but over time, the potential for aggressive, erosive, and deforming disease has been recognized [3]. PsA is a member of a larger group of inflammatory arthritides called the spondyloarthropathies. This group also includes ankylosing spondylitis, reactive arthritis, enteropathic arthritis (associated with inflammatory bowel disease), and undifferentiated spondyloarthropathy.

The key features of PsA are inflammatory arthritis, enthesitis, dactylitis, and spondylitis (Table 1). Patients may have any combination of these features. Inflammatory arthritis or synovitis is distinguished from noninflammatory arthritis by swelling, warmth, tenderness, and erythema, although not all inflamed joints will have all of these features. A distinguishing feature between PsA and other inflammatory arthritides is the involvement of the distal interphalangeal joints (DIPs). Dactylitis and enthesitis are both characteristic features of spondyloarthropathies (such as PsA) and are important to recognize. Dactylitis (also known as "sausage toe" or "sausage finger") 
Table 1 Key features of psoriatic arthritis

\begin{tabular}{|c|c|c|c|c|}
\hline Feature & Inflammatory arthritis & Enthesitis & Dactylitis & Spondylitis \\
\hline Definition & $\begin{array}{l}\text { Also known as "synovitis:" } \\
\text { inflammation of the synovium } \\
\text { (the lining of the joints) }\end{array}$ & $\begin{array}{l}\text { Inflammation of the } \\
\text { enthesis, or site where } \\
\text { ligaments, tendons, } \\
\text { and/or fascia attach to } \\
\text { bone }\end{array}$ & $\begin{array}{l}\text { Inflammation of the entire } \\
\text { digit, including the joints, } \\
\text { adjacent soft tissues, and } \\
\text { tendons }\end{array}$ & $\begin{array}{l}\text { Inflammation of one or more } \\
\text { vertebrae (intervertebral } \\
\text { and costovertebral joints), } \\
\text { or of the sacroiliac (SI) } \\
\text { joints (sacroiliitis) }\end{array}$ \\
\hline History & $\begin{array}{l}\text { History of prolonged morning } \\
\text { stiffness ( }>30-45 \mathrm{~min}) \text {; joint pain } \\
\text { that improves with activity and } \\
\text { worsens with rest; any joint can } \\
\text { be affected, though DIP } \\
\text { involvement raises suspicion for } \\
\text { PsA over other types of } \\
\text { inflammatory arthritis. }\end{array}$ & $\begin{array}{l}\text { Pain at the heel, tibial } \\
\text { tuberosity, iliac crest, } \\
\text { and other tendon } \\
\text { insertion sites [4-6] }\end{array}$ & $\begin{array}{l}\text { Pain, swelling, and/or } \\
\text { warmth of an entire digit }\end{array}$ & $\begin{array}{l}\text { Back or hip pain that is } \\
\text { worse in the mornings } \\
\text { (with }>1 \text { hour of morning } \\
\text { stiffness) }\end{array}$ \\
\hline Exam features & $\begin{array}{l}\text { Swelling, warmth, tenderness, and/ } \\
\text { or erythema of the joints (with a } \\
\text { classic "boggy" sensation); not } \\
\text { all inflamed joints will have all of } \\
\text { the exam features }\end{array}$ & $\begin{array}{l}\text { Tenderness, warmth, and/ } \\
\text { or swelling at enthesis, } \\
\text { particularly the Achilles } \\
\text { tendon in PsA [6] }\end{array}$ & $\begin{array}{l}\text { Swelling, warmth, and/or } \\
\text { erythema of the entire digit } \\
\text { from its base (also known } \\
\text { as "sausage toe" or } \\
\text { sausage finger"); this is } \\
\text { unlike synovitis, where } \\
\text { inflammation is confined } \\
\text { to the joints }\end{array}$ & $\begin{array}{l}\text { Paravertebral and/or SI } \\
\text { joint tenderness; } \\
\text { abnormal Schober's test* }\end{array}$ \\
\hline
\end{tabular}

*Modified Schober's test: the examiner makes a mark at the level of L5 (fifth lumbar vertebrae). He then makes a second mark at $5 \mathrm{~cm}$ below the L5 mark and another at $10 \mathrm{~cm}$ above the L5 mark. The patient is asked to touch his toes. By doing so, the distance between the second and third marks should increase by at least $5 \mathrm{~cm}$. If the distance increases less than $5 \mathrm{~cm}$, it indicates reduced lumbar flexion due to possible vertebral inflammation $[4,5]$

involves swelling of the entire digit from its base, unlike synovitis in which swelling is confined to the joints. This is a result of inflammation in the adjacent soft tissues and tendons. Enthesitis (or enthesopathy) refers to inflammation at the site where ligaments, tendons, and/or fascia attach to bone. The enthesis is composed of dense collagen and fibrocartilage and is adjacent to bursae and synovial tissue [7]. Enthesitis is usually associated with history of discomfort in the tendon or ligament, morning stiffness, and on examination, there is generally tenderness, warmth, and/or swelling. Enthesitis can occur at many sites, but the most common sites are the insertion of the Achilles tendon into the calcaneus and the plantar fascia. Spondylitis is defined as inflammation of one or more vertebrae (intervertebral and costovertebral joints) or of the sacroiliac (SI) joints (sacroiliitis). Patients with spondylitis present with back or gluteal pain that is typically worse in the mornings with greater than an hour of morning stiffness $[4,5]$.

Several patterns of joint involvement in PsA have been identified: monoarthritis, oligoarthritis (less than 5 joints affected in an asymmetric distribution), polyarthritis (similar to and at times indistinguishable from RA), distal interphalangeal joint (DIP) joint predominant arthritis, arthritis mutilans (characterized by deforming and destructive arthritis), and psoriatic spondylitis (including both sacroiliitis and spondylitis). Patients also may present with predominantly enthesial inflammation. Clinical presentation is quite variable with many patients having more than one feature. Moll and Wright initially described the most prevalent subgroup as oligoarthritis [8], but clinical patterns in recent studies have varied depending on the population observed [3, 9-15]. Among two studies observing patients with psoriasis in a dermatology clinic, one reported $59 \%$ polyarthritis and $32 \%$ oligoarthritis among those with PsA [16] and another reported $31 \%$ polyarthritis and $31 \%$ oligoarthritis [17]. The latter study excluded those with previously diagnosed PsA. Because patients with oligoarthritis may progress to polyarthritis, length of disease and therapies used among those with PsA may influence the prevalence of either subtype.

\section{Defining PsA}

The original diagnostic criteria of Moll and Wright were developed in 1973 [8] and include the following:

- inflammatory arthritis (peripheral arthritis and/or sacroiliitis or spondylitis)

- presence of psoriasis

- (usual) absence of serological tests for rheumatoid factor.

Although the Moll and Wright criteria continue to be widely used, they have been shown to discriminate poorly between PsA and RA [18]. Since that time, several classification criteria have been developed [19-24]. It is important to note that classification criteria are developed to provide uniform definitions for inclusion in research studies. While developed for use in research, these criteria also can be 
helpful in guiding diagnosis in clinical practice [25]. Development of the ClASsification criteria for Psoriatic Arthritis (CASPAR) criteria in 2006 provided a promising framework for conducting clinical research in PsA, given its high sensitivity and specificity (each $>0.9$ ) in the rheumatology, early arthritis, and family practice settings (Table 2) [23, 25-29]. CASPAR criteria are currently the most widely accepted tool for defining PsA in clinical research studies and are commonly used to guide the diagnosis of PsA in clinical practice.

\section{Onset of PsA Relative to Psoriasis Onset}

Approximately $67 \%$ of patients develop psoriasis before arthritis, and for approximately $16 \%$ of patients, arthritis and psoriasis present within 12 months of each other [30]. The remainder-approximately $17 \%$ - develop arthritis before psoriasis [15]. On average, the onset of inflammatory arthritis tends to occur between 7 to 10 years after the onset of psoriasis [3]. Thus, studies have demonstrated an increasing cumulative incidence of PsA with increasing duration of psoriatic disease [31•].

\section{Age and Gender Distribution}

The mean age at onset of PsA is during approximately the fourth decade [31•, 32-38]. PsA affects men and women approximately equally [3]; the percentage of affected females ranged from $38.4 \%$ to $60 \%$ in the most recent studies [31•, 32-39].

\section{Epidemiology of Psoriatic Arthritis}

\section{Incidence and Prevalence of PsA}

Previous studies from various parts of the world have suggested a wide variation in the incidence and prevalence of PsA in the general population. Systematic reviews in 2008 and 2012 identified studies from several different countries from

Table 2 CASPAR criteria

A patient with inflammatory arthritis, spondylitis, or enthesitis and $\geq 3$ points from the following elements

\begin{tabular}{ll}
\hline Feature & Points \\
Current psoriasis & 2 \\
History of psoriasis (unless current psoriasis was present) & 1 \\
$\begin{array}{l}\text { Family history of psoriasis (unless current psoriasis or a } \\
\text { history of psoriasis was present) }\end{array}$ & 1 \\
Dactylitis & 1 \\
Juxta-articular new bone formation & 1 \\
Rheumatoid factor negativity & 1 \\
Typical psoriatic nail dystrophy & 1 \\
\hline
\end{tabular}

their literature search $[40,41]$. In these reviews, the incidence of PsA varied from 0.1 to 23 cases per $10^{\wedge} 5$ inhabitants (median 6.4 cases). Prevalence estimates varied from 1 case per $10^{\wedge} 5$ inhabitants in Japan to 420 cases per $10^{\wedge} 5$ inhabitants in Italy. Of note, these studies used different definitions for PsA, including the European Spondylarthropathy Study Group (ESSG) criteria, CASPAR criteria, diagnostic codes for PsA in the medical record, and coexisting psoriasis and arthritis, likely contributing to the observed variation. Additional studies have subsequently published results comparable to what were noted in these reviews [32, 33, 42, 43].

Estimates of the prevalence of PsA among patients with psoriasis have varied from $6-39 \%[16,34,44-47]$. The highest estimates of PsA among patients with psoriasis are generally derived from dermatology clinics, possibly due to the increased severity of psoriasis in the dermatology clinic relative to the general population. Less is known about the incidence of PsA among patients with psoriasis. A retrospective study from Germany reported that the incidence of PsA among psoriasis patients remained constant (74 per 1,000 person-years), whereas the prevalence increased with time since diagnosis of psoriasis, reaching $20.5 \%$ after 30 years [48]. Another retrospective study from Minnesota found a lower cumulative incidence of $3.1 \%$ of cases of PsA among psoriasis patients after 10 years from the onset of skin disease [31•]. The first study to prospectively assess the incidence of PsA among psoriasis patients was conducted in Toronto recently; 313 psoriasis patients who had at least 1 year of follow-up were included in the analysis. The annual incidence rate was found to be 1.87 (95\% confidence interval (CI) 0.71 3.03) PsA cases per 100 psoriasis patients [3].

\section{Risk Factors for Developing Psoriatic Arthritis Among Patients with Psoriasis}

Risk factors for the development of PsA may help to identify patients with psoriasis who should be screened for PsA or watched carefully for the development of joint symptoms. Early identification of patients at risk, in addition to lifestyle modifications, could help to prevent future joint damage and functional impairment [39]. Several noteworthy studies have addressed risk factors for PsA and have suggested that psoriasis severity, nail dystrophy [31•], smoking [49•], trauma [50], obesity [51•], obesity at the age of 18 years [52•], and prior glucocorticoid use [53] are risk factors for PsA. However, note that these findings are associations and do not necessarily reflect causation.

\section{Smoking}

A number of studies have examined smoking as a risk factor for the development of psoriasis and psoriatic arthritis, although conflicting evidence exists. Although previous 
studies have suggested that smoking is a risk factor for the development of psoriasis [54], the association with the development of PsA is less clear. Two studies (notably within the same cohort) suggest that there is an inverse association between smoking and PsA among patients with psoriasis (e.g., smoking is protective, similar to findings in ulcerative colitis) $\left[55^{\bullet}, 5^{\bullet}\right]$. However, another study suggests that smoking is positively associated with development of PsA [49•]. In this latter study, 157 incident PsA cases were identified. Compared with never smokers, the relative risk (RR) for developing PsA was 1.54 for past smokers (95\% CI 1.06-2.24) and 3.13 for current smokers (95\% CI 2.08-4.71). With increasing smoking duration or pack-years, the risk of PsA increased monotonically ( $p$ for trend $<0.0001$ ). The population in this study was all women in the Nurses Health Study II cohort (not patients with psoriasis as in the previous studies). In this case, one may hypothesize that smoking drives psoriasis, which then drives PsA, and thus psoriasis is a mediator in the relationship between smoking and PsA. However, the results persisted even after restricting the cohort to women with a prior diagnosis of psoriasis. Smoking may play a role in the development of PsA by inducing oxidative stress that leads to an imbalance of oxidants and antioxidants resulting in chronic inflammation of the joints [57, 58]. Smoking also adversely alters the immunologic and inflammatory processes, which could contribute to the development of PsA $[59,60]$. On the contrary, one theory to explain the inverse association between smoking and PsA is through the activation of the nicotinic receptor. Nicotine can activate the $\alpha 7$ nicotinic acetylcholine receptor that inhibits intracellular proinflammatory pathways that are associated with the development of arthritis [61].

\section{Severity of Psoriasis}

Several cross-sectional studies have shown that the prevalence of PsA is increased among patients with severe psoriasis $[31 \bullet, 62]$. This may make sense biologically but also may represent observation bias in that patients with more extensive psoriasis may be followed more closely by physicians and therefore are more likely to have their inflammatory arthritis come to medical attention. Although studies suggest an increasing prevalence of PsA with increasing psoriasis severity, at any one time point, the disease activity in the skin and joints does not necessarily correlate (e.g., one can be flaring while the other is stable). Additionally, it is important to recognize that the majority of patients with PsA have mild psoriasis and a relatively small proportion of patients with psoriasis have severe disease [63].

\section{Nail Dystrophy}

Typical psoriatic nail dystrophy is a known risk factor for development of PsA [31•]. Recent studies have shown that nail changes are more frequent in patients with PsA compared with those with psoriasis alone $[14,56]$ and that nail changes were more frequent in the PsA patients with distal interphalangeal joint (DIP) involvement than those without DIP involvement ( $63 \%$ vs. $41.2 \%, P<0.05$ ) [15]. Interestingly, an ultrasound study in 2012 showed that nail involvement in psoriasis also is associated with a higher systemic enthesopathy score [64•]. It is unclear why nail dystrophy may be associated with a higher risk of PsA. It is possible that dystrophic nails represent a marker for immunoreactivity, leading to PsA in a subset of psoriasis patients. A study by Scarpa and colleagues noted that nail involvement is present in almost all PsA even if it is not clinically evident. Furthermore, given the close proximity of the DIP joint to the nail matrix, they postulated that DIP joint involvement may actually occur as a result of nail disease [65]. This study raises the possibility that nail dystrophy is an indicator of ongoing DIP involvement.

\section{Location of Psoriasis}

Wilson et al. found that patients with psoriasis involving the intergluteal and/or perianal areas and psoriasis involving more than three affected areas had a higher risk of developing PsA, with a hazard ratio (HR) of 2.35 (95\% CI, 1.324.19) and HR 2.24 (95\% CI, 1.23-4.08), respectively [31•]. In addition, studies have shown that scalp psoriasis is seen more frequently in PsA patients compared with patients with psoriasis only $[15,31 \bullet]$. Some argue, however, that because the scalp is commonly one of the first areas affected by psoriasis [66] that patients with more severe psoriasis (and likely a higher chance of developing PsA as discussed above) will inevitably have more scalp disease.

\section{Obesity}

Obesity has been associated with an increased risk of psoriasis [67], and more recent studies have found associations between obesity and PsA. In cross-sectional studies, PsA patients had a higher body mass index (BMI) than healthy controls $[68,69]$ and PsA was more prevalent among obese psoriasis patients than nonobese psoriasis patients [62]. The directionality of this association is still relatively unclear. Is it that patients with PsA have difficulty with mobility and thus become obese or does obesity predispose the patient to development of inflammatory arthritis because of biochemical or mechanical factors? Studies to date suggest the former [70, 71], but the relationship is confusing given that the incidence of joint pain and osteoarthritis is more prevalent among obese individuals [72], creating a potential for misclassification bias. However, a recent cohort study found that the incidence of PsA increased with increasing BMI. Compared with psoriasis patients with BMI $<25 \mathrm{~kg} / \mathrm{m}^{2}$, the 
RRs for developing PsA were 1.09 (0.93-1.28) for BMIs from 25.0 to $25.9,1.22(1.02-1.47)$ for BMIs from 30.0 to 34.9 , and $1.48(1.20-1.81)$ for BMIs $\geq 35$ [50].

\section{Markers of Progression in Patients with Psoriatic Arthritis}

Although psoriatic arthritis was once thought to be a milder disease than rheumatoid arthritis, we now know that it can be quite destructive with nearly $20 \%$ of patients disabled by their disease [73]. In addition, this destruction can happen quite early in the disease course; approximately half develop radiographic damage in a median of 2 years after symptom onset [74]. Although disease course is as variable as the clinical phenotypes of PsA, the number of actively inflamed joints (and particularly swollen joints) is associated with both radiographic damage and clinically apparent damage, defined as decreased range of motion of the joint, joint deformities, loosening, or ankylosis $[75,76]$. Furthermore, tenderness and swelling of a joint can predict damage to that particular joint [77]. Simon et al. also found that an increasing joint count over the course of the retrospective study correlated with radiographic progression [76]. Finally, among the placebo group in a phase III clinical trial (ADEPT), elevated CRP at baseline was a risk factor for radiographic progression [78].

\section{Identification of Early Psoriatic Arthritis}

Previous reports have suggested that approximately $10 \%$ of patients with psoriasis followed in a dermatology clinic have undiagnosed PsA, although this may be an underestimate. Haroon et al. recently reported that, after excluding patients with known PsA, $29 \%$ patients with psoriasis systematically assessed for PsA had the disease [17]. Ibrahim et al. found that among 93 patients with psoriasis, 12 had PsA and of these, only 4 had a previously known diagnosis of PsA [79]. Not only is PsA underdiagnosed, but the diagnosis often is delayed when made. Given the high burden of radiographic disease even early in the disease course [74], it is important to identify patients with PsA early in their course because early initiation of treatment may improve the disease course. Although evidence for early treatment initiation does not yet exist in PsA [80], in RA early initiation of therapy (e.g., methotrexate) results in improved response to therapy and decreased erosions at 2 years compared with those with later treatment initiation ( $>3$ months after symptom onset) [81-84]. A recent observational study by Gladman et al. provided support for this concept; patients who presented after 2 years of symptoms had a much greater rate of progression than those who presented earlier in the disease course [85]. Dermatologists play a key role in identification of PsA, because patients often are unaware of the association between their skin condition and joint symptoms.

\section{Screening Tools}

Whereas dermatologists will have varying comfort in assessing for PsA, simple screening tools have been developed to help identify which patients should receive further evaluation for the diagnosis of PsA. Four screening tools have been developed to date (Table 2): the Psoriasis Epidemiology Screening Tool (PEST), Toronto Psoriatic Arthritis Screening (ToPAS), Psoriasis and Arthritis Screening Questionnaire (PASQ), and Psoriatic Arthritis Screening and Evaluation (PASE). These tools were designed specifically to help dermatologists identify those patients with psoriasis who would benefit from a prompt referral to rheumatology. All are one- or two-page questionnaires that can be easily administered during office visits and performed relatively similarly, with sensitivities ranging from $76 \%$ to $92 \%$ and specificities ranging from $73 \%$ to $93 \%$ in the original validation studies [86-90]. An electronic version of the PASQ tool (ePASQ) was recently created and is available for download on the Ipad and Iphone at the App store [91]. There is no preference for one tool over another. Of note, a positive screening questionnaire does not mean the patient has PsA. Mimics of PsA, such as osteoarthritis, fibromyalgia, gout, pseudogout, and RA, also may screen "positive."

It is important to recognize that these screening questionnaires, while they can be helpful, have been found to have much lower sensitivity and specificity than those reported in the initial validation studies, particularly when applied among psoriasis patients without known PsA (the original validation studies included patients with known PsA) [88-90]. Compared with a rheumatologist's assessment ("gold standard"), the sensitivities of these instruments ranged from $24-41 \%$ and specificities ranged from 90 $98 \%$ in a recent study by Haroon et al. among patients with psoriasis but without known PsA. Positive and negative predictive values also were lower than previous described: $63-88 \%$ and $75-82 \%$ respectively [17]. Walsh et al. performed a similar study and found sensitivity $60-76 \%$ and specificity $41-55 \%$ after excluding those with known PsA [92]. The results of these recent studies question the usefulness of the existing questionnaires and suggest the need for the development of new instruments.

\section{Evaluation of the Patient with Psoriasis and Joint Pain}

The differential diagnosis for joint pain in a patient with psoriasis is broad. As mentioned earlier, it includes psoriatic arthritis, osteoarthritis, fibromyalgia, gout, pseudogout, RA, other spondyloarthropathies, overuse syndromes, and mechanical- and trauma-related joint pain. Historical elements suggestive of inflammatory arthritis include severe and persistent pain for $>6$ weeks, morning stiffness (or 
stiffness after prolonged rest) lasting $>30$ minutes, systemic symptoms, such as fatigue, and swelling of the joints [93, 94]. History of dactylitis or swelling of the entire digit such that it appears like a "sausage" is highly suggestive of psoriatic arthritis. Quick screening questions for inflammatory arthritis include the presence of joint pain, prolonged morning stiffness, and joint swelling.

Physical examination is still the "gold standard" for diagnosing inflammatory arthritis. Examination features are noted in Table 1. Synovitis has been described as a "spongy" feeling as if there is a "layer of bread dough between the skin and bony margins of the joint [95]." This is distinct from bony enlargement and crepitus (crackling feeling while moving the joint through the range of motion) felt on examination of the osteoarthritic joint. Tenderness over the joint lines can be suggestive of inflammation, although this can be present in the other conditions mentioned as well. Examination of the entheses is best accomplished by applying pressure over the area where the tendon inserts onto the bone and assessing for tenderness. For example, pressure is applied over the region where the Achilles tendon inserts onto the calcaneous. Inflammation in the entheses can be difficult to visualize. The Group for Research and Assessment of Psoriasis and Psoriatic Arthritis (GRAPPA) has developed videos to teach dermatologists examination techniques for identifying PsA. These are currently only available to GRAPPA members but will soon be widely available (the web address was not available at the time of publication) [96].

No laboratory biomarkers are available for diagnosing PsA, and there are not specific recommendations for laboratory workup of suspected inflammatory arthritis, because this is usually driven by the clinical history [97]. An elevated C-reactive protein (CRP) and/or sedimentation rate may suggest systemic inflammation. However, these inflammatory markers can be normal in approximately half of patients with active PsA and can be elevated in patients with psoriasis but without arthritis. Rheumatoid factor (RF) and anticyclic citrullinated peptide (CCP) can be used to evaluate for RA in the setting of polyarthritis, although $10-20 \%$ of patients with PsA will have a positive RF. Anti-CCP also can be positive in PsA. A negative RF is helpful, because it satisfies an element of the CASPAR criteria.

There is no consensus on the need for imaging studies in diagnosis and/or monitoring of PsA. Plain film radiographs (x-rays) of the joints involved can be useful if new bone formation, erosions, osteolysis, or ankylosis are present [98]. However, early in the course of the disease, these findings most often will not be apparent. Musculoskeletal ultrasound (US) is increasingly used to aid in diagnosis. When there is a question about the examination a joint or enthesis, US can be helpful to establish whether or not inflammation is present. US detects entheseal abnormalities, including tendon edema and thickening, tendon tears, bone erosions, enthesophytes, bursitis, and increased blood perfusion via power Doppler [99]. Magnetic resonance imaging (MRI) is useful to assess the spine and sacroiliac joints, because inflammation in these areas often is missed on X-rays [100].

Although there is no consensus for which patients should be referred to rheumatologist and what initial workup should be performed, we propose the algorithm shown in Figure 1. One of the difficulties when diagnosing inflammatory arthritis is that not all joint pain represents inflammation and the reasons for joint pain can be very difficult to distinguish, even for experienced rheumatologists. Therefore, we strongly recommend that all patients suspected of having inflammatory arthritis be seen by a rheumatologist for confirmation of the diagnosis and therapy initiation. After the diagnosis has been confirmed, the rheumatologist and dermatologist should work together to manage the patient's symptoms.

\section{Treatment of Psoriatic Arthritis}

A full discussion of treatment is beyond the scope of this review. The treatment of psoriatic arthritis can be complex, because it often is tailored to the manifestations of the disease. For example, spondylitis, dactylitis, and enthesitis often respond best to TNF-alpha inhibitors rather than traditional disease modifying antirheumatic drugs. We suggest referring to the GRAPPA guidelines or the European Union League Against Rheumatism (EULAR) treatment recommendations [101-104]. However, it is important to note that these guidelines are in flux given recent evidence suggesting that methotrexate may not act as a disease modifying agent in the treatment of PsA [105, 106]. Furthermore, there are several new drugs in the pipeline for the treatment of PsA.

\section{Other Considerations}

\section{Cardiovascular Disease}

Multiple studies have now demonstrated the increased risk of cardiovascular disease (CVD) in patients with psoriasis but fewer studies specifically examine PsA. These studies suggest that patients with PsA also are at an increased risk for developing CVD [107-109]. CVD is among the leading causes of death in patients with PsA [110, 111]. Furthermore, traditional cardiovascular risk factors (hypertension, diabetes, and hyperlipidemia) as well as peripheral vascular disease, congestive heart failure, atherosclerosis, and ischemic heart disease are more prevalent among patients with PsA than controls [107]. Patients with PsA may be at increased risk for developing diabetes [112]. A recent study examining the association between PsA and CVD in a large cohort of U.S. women found 
Fig. 1 Suggested workup for patients with suspected inflammatory arthritis. It may be most cost-effective to allow the rheumatologist to order additional studies, such as labs and imaging; however, optional studies are suggested here. Many rheumatologists will check hepatitis serologies before institution of DMARDs and testing for tuberculosis is required before initiation of a TNF-alpha inhibitor. Studies have suggested that response to vaccinations is dampened by use of DMARDs, particularly the TNF-alpha inhibitors. Therefore, vaccination before initiating therapy is beneficial. PPD, purified protein derivative; $\mathrm{HCV} / \mathrm{HBV}$, hepatitis $\mathrm{C}$ virus and hepatitis $B$ virus

\begin{tabular}{|c|c|}
\hline $\begin{array}{l}\text { Elements Suggesting Possible } \\
\text { Inflammatory Arthritis }\end{array}$ & $\begin{array}{l}\text { Optional Studies Prior to First } \\
\text { Rheumatology Visit }\end{array}$ \\
\hline $\begin{array}{l}\text { History } \\
\text { - Joint pain lasting }>6 \text { weeks } \\
\text { - Morning stiffness lasting }>30-45 \\
\text { minutes } \\
\text { - Persistent joint swelling } \\
\text { - Dactylitis (e.g. swelling of a whole } \\
\text { finger or toe like a sausage) } \\
\text { - Positive screening questionnaire } \\
\text { History of nail aystrophy cma family history of } \\
\text { sponaylocrthritis cre also supportive of PsA } \\
\text { in a patient with one of the above elements. } \\
\quad \text { Examination } \\
\text { - Warmth, tenderness or swelling over } \\
\text { a joint and/or tendon } \\
\text { Tenderness over the sacroiliac joints }\end{array}$ & 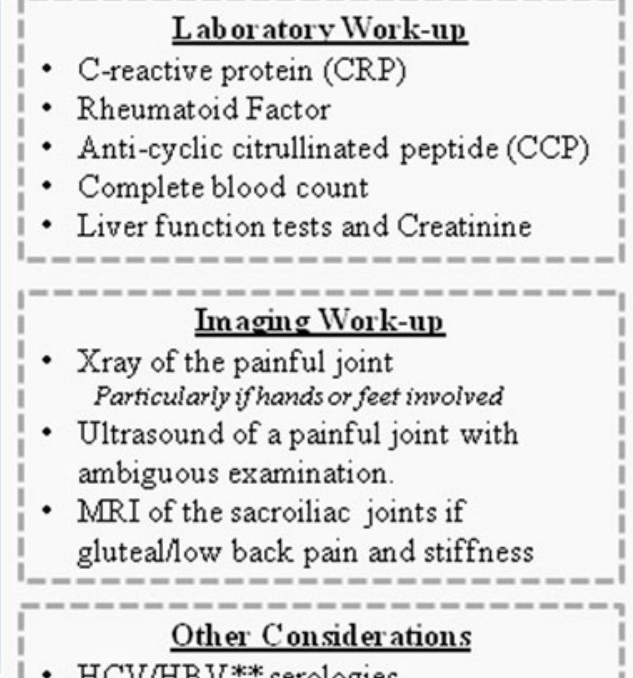 \\
\hline Refer to Rheumatologist & $\begin{array}{l}\text { - } \mathrm{HCV} / \mathrm{HBV} * * \text { serologies } \\
\text { Testing for Latent Tuberculosis (e.g. } \\
\text { PPD*or Quantiferon Gold) } \\
\text { Vaccinations (e.g. influenza, tetanus, } \\
\text { pneumovax, and/or varicella as }\end{array}$ \\
\hline \multicolumn{2}{|c|}{$\begin{array}{l}\text { Figure 1. Suggested Work up for Patients with Suspected Inflammatory Arthitis. It may be } \\
\text { most cost-effective to allow the rheumatologist to order additional studies such as labs and imaging, } \\
\text { however, optional studies are suggested here. Many rheumatologists will check hepatitis serologies } \\
\text { prior to institution of DMARDs and testing for tuberculosis is required prior to initiation of a TNF } \\
\text { alpha inhibitor. Studies have suggested that resp onse to vaccinations is dampened by use of } \\
\text { DMARDs, particularly the TNF-alphainhibitors. Therefore, vaccination prior to initiating therapy is } \\
\text { beneficial. *PPD - purified protein derivative, **HCV/HBV - hepatitis C vinus and hepatitisB vinus. }\end{array}$} \\
\hline
\end{tabular}

a significantly elevated risk of nonfatal CVD, particularly MI, in women with PsA, even after adjusting for traditional cardiovascular risk factors. Adjusted hazard ratios (95\% CI) for nonfatal CVD, nonfatal myocardial infarction (MI), and nonfatal stroke were 5.32 (2.85-9.94), 7.4 (3.5-15.66), and 3.18 (1.02-9.91) respectively [113••]. Even patients with early PsA (diagnosis within 2 years) seemingly incur this risk [114]. Health care providers should be aware of the increased risk for CVD in patients with PsA, counsel patients on these comorbid conditions, and refer to primary care or cardiology specialty care accordingly for management.

\section{Summary}

- PsA can be monoarticular, oligoarticular, or polyarticular inflammatory arthritis. Additional features include spondylitis, arthritis mutilans, enthesitis, and dactylitis.

- The CASPAR criteria are classification criteria most often used to define PsA in research studies, and although designed for the purpose of research, are most helpful in clinical practice.

- There is a wide variation of incidence and prevalence of PsA in the world, and prevalence of PsA in psoriasis ranges from 6-39\%. This is likely due, in part, to varied study designs and definitions of PsA.

- The average age of onset for PsA is in the mid 40s. PsA most often occurs years after the onset of psoriasis but can occur before or at the same time as the onset of clinically apparent skin disease.

- Potential risk factors for PsA include nail involvement, obesity, severity/location of psoriasis, and smoking.

- There are four main screening tools for PsA: (PEST), (ToPAS), (PASQ), and (PASE). These can be used easily in an office setting to determine which patients would benefit from a referral to a rheumatologist.

- Physicians who treat individuals with psoriasis and PsA should address modifiable CVD risk factors. These include smoking, obesity, hypertension, hyperlipidemia, and diabetes. 
Acknowledgment The authors thank Yihui Connie Jiang for administrative support in assembling this paper.

Disclosures K.M. Koolaee has reported no potential conflicts of interest relevant to this article; J. Takeshita has received a grant from the National Psoriasis Foundation; and A. Ogdie is supported by the American College of Rheumatology Research and Education Foundation Rheumatology Investigator Award.

\section{References}

Papers of particular interest, published recently, have been highlighted as:

- Of importance

- Of major importance

1. Picchianti-Diamanti A, Germano V, Ferlito C, Migliore A, D'Amelio R, Laganà B. Health-related quality of life and disability in patients with rheumatoid, early rheumatoid and early psoriatic arthritis treated with etanercept. Qual Life Res. 2010;19 (6):821-6.

2. Kavanaugh A, Antoni C, Krueger GG, Yan S, Bala M, Dooley LT. Infliximab improves health related quality of life and physical function in patients with psoriatic arthritis. Ann Rheum Dis. 2006;65(4):471-7.

3. Kimball AB, Gladman D, Gelfand JM, Gordon K, Horn EJ, Korman NJ. National psoriasis foundation clinical consensus on psoriasis comorbidities and recommendations for screening. $\mathrm{J}$ Am Acad Dermatol. 2008;58(6):1031-42.

4. Sieper J, Rudwaleit M, Baraliakos X, Brandt J, Braun J, BurgosVargas R. The Assessment of SpondyloArthritis international Society (ASAS) handbook: a guide to assess spondyloarthritis. Ann Rheum Dis. 2009;68(Suppl 2:ii):1-44.

5. Sieper J, van der Heijde D, Landewe R, Brandt J, Burgos-Vagas R. New criteria for inflammatory back pain in patients with chronic back pain: a real patient exercise by experts from the Assessment of SpondyloArthritis international Society (ASAS). Ann Rheum Dis. 2009;68:784-8.

6. Coates LC, Helliwell PS. Disease measurement-enthesitis, skin, nails, spine and dactylitis. Best Pract Res Clin Rheumatol. 2010;24(5):659-70.

7. D'Agostino MA, Olivieri I. Enthesitis. Best Pract Res Clin Rheumatol. 2006;20(3):473-86.

8. Moll JM, Wright V. Psoriatic arthritis. Semin Arthritis Rheum. 1973;3(1):55-78.

9. Alonso JCT, Perez AR, Castrillo JMA, Garcia JB, Noriega JLR, Larrea CL. Psoriatic arthritis (PA): a clinical, immunological and radiological study of 180 patients. Br J Rheumatol. 1991;30 (4):245-50.

10. Biondi OC, Scarpa R, Pucino A, Oriente P. Psoriasis and psoriatic arthritis. Dermatological and rheumatological co-operative clinical report. Acta Derm Vene. 1989;146:69-71.

11. Helliwell P, Marchesoni A, Peters M, Barker M, Wright V. A reevaluation of the osteoarticular manifestations of psoriasis. Br J Rheumatol. 1991;30(5):339-45.

12. Jones SM, Armas JB, Cohen MG, Lovell CR, Evison G, McHugh NJ. Psoriatic arthritis: outcome of disease subsets and relationship of joint disease to nail and skin disease. Br J Rheumatol. 1994;33 (9):834-9.

13. Gladman DD, Shuckett R, Russell ML, Thorne JC, Schachter RK. Psoriatic arthritis (PSA) - an analysis of 220 patients. Q J Med. 1987;62(238):127-41.
14. Veale D, Rogers S, Fitzgerald O. Classification of clinical subsets in psoriatic arthritis. Br J Rheumatol. 1994;33(2):133-8.

15. Yang Q, Qu L, Tian H, Hu Y, Peng J, Yu X. Prevalence and characteristics of psoriatic arthritis in Chinese patients with psoriasis. J Eur Acad Dermatol Venereol. 2011;25(12):1409-14.

16. Reich K, Krüger K, Mössner R, Augustin M. Epidemiology and clinical pattern of psoriatic arthritis in Germany: a prospective interdisciplinary epidemiological study of 1,511 patients with plaque-type psoriasis. Br J Dermatol. 2009;160(5):1040-7.

17. Haroon M, Kirby B, FitzGerald O. High prevalence of psoriatic arthritis in patients with severe psoriasis with suboptimal performance of screening questionnaires. Ann Rheum Dis.

18. Helliwell PS, Taylor WJ. Classification and diagnostic criteria for psoriatic arthritis. Ann Rheum Dis. 2005;64(Suppl 2:ii):3-8.

19. Bennett RM. Psoriatic arthritis. In: McCarty DJ, editor. Arthritis and allied conditions. 9th ed. Philadelphia: Lea \& Feb; 1979. p. 645.

20. Fournie B, Crognier L, Arnaud C, Zabraniecki L, LascauxLefebvre V, Marc V. Proposed classification criteria of psoriatic arthritis: a preliminary study in 260 patients. Rev Rhum Engl Ed. 1999;66(10):446-56.

21. Dougados M, van der Linden S, Juhlin R, et al. The European spondylarthropathy study group preliminary criteria for the classification of spondylarthropathy. Arthritis Rheum. 1991;34(10):1218-27.

22. McGonagle D, Conaghan PG, Emery P. Psoriatic arthritis: a unified concept twenty years on. Arthritis Rheum. 1999;42 (6): $1080-6$.

23. Taylor W, Gladman D, Helliwell P, Marchesoni A, Mease P, Mielants H. Classification criteria for psoriatic arthritis: development of new criteria from a large international study. Arthritis Rheum. 2006;54(2):665-73.

24. Vasey F, Espinoza LR. Psoriatic arthropathy. In: Calin A, editor. Spondyloarthropathies. Orlando: Grune \& Stratton; 1984. p. 151-85.

25. Johnson SR, Goek ON, Singh-Grewal D, Vlad SC, Feldman BM, Felson DT. Classification criteria in rheumatic diseases: a review of methodologic properties. Arthritis Rheum. 2007;57(7):1119-33.

26. Congi L, Roussou E. Clinical application of the CASPAR criteria for psoriatic arthritis compared to other existing criteria. Clin Exp Rheumatol. 2010;28:304-10.

27. Chandran V, Schentag CT, Gladman DD. Sensitivity of the classification of psoriatic arthritis criteria in early psoriatic arthritis. Arthritis Rheum. 2007;57(8):1560-3.

28. Chandran V, Schentag CT, Gladman DD. Sensitivity and specificity of the CASPAR criteria for psoriatic arthritis in a family medicine clinic setting. J Rheumatol. 2010;35(10):2069-70.

29. D'Angelo S, Mennillo G, Cutro M, Leccese P, Nigro A, Padula A. Sensitivity of the classification of psoriatic arthritis criteria in early psoriatic arthritis. J Rheumatol. 2009;36(2):368-70.

30. Gladman DD. Psoriatic arthritis. In: Gordon K, Ruderman E, editors. Psoriasis and psoriatic arthritis. Berlin: Spinger-Verlag; 2005. p. 57-65.

31. - Wilson FC, Icen M, Crowson CS, McEvoy MT, Gabriel SE, Kremers HM. Incidence and clinical predictors of psoriatic arthritis in patients with psoriasis: a population-based study. Arthritis Rheum. 2009;61(2):233-9. A cohort of 1,593 patients with psoriasis was assessed over 20,936 person-years of follow-up to determine predictors of PsA. Psoriasis features associated with a higher risk of PSA were scalp lesions (HR 3.89, $95 \%$ CI 2.186.94), nail dystrophy (HR 2.93, $95 \%$ CI 1.68-5.12), and intergluteal/perianal lesions (HR 2.35, $95 \%$ CI 1.32-4.19).

32. Haglund E, Bremander AB, Petersson IF, Strömbeck B, Bergman S, Jacobsson LT. Prevalence of spondyloarthritis and its subtypes in southern Sweden. Ann Rheum Dis. 2011;70(6):943-8.

33. Soriano ER, Rosa J, Velozo E, Schpilberg M, Imamura PM, Diaz J. Incidence and prevalence of psoriatic arthritis in Buenos Aires, Argentina: a 6-year health management organization-based study. Rheumatology (Oxford). 2011;50(4):729-34. 
34. Shbeeb M, Uramoto KM, Gibson LE, O'Fallon WM, Gabriel SE. The epidemiology of psoriatic arthritis in Olmsted County, Minnesota, USA, 1982-1991. J Rheumatol. 2000;27(5):1247-50.

35. Andrianakos A, Trontzas P, Christoyannis F, Dantis P, Voudouris C, Georgountzos A. Prevalence of rheumatic diseases in Greece: a cross-sectional population based epidemiological study. The ESORDIG Study J Rheumatol. 2003;30(7):1589-601.

36. Saraux A, Guillemin F, Guggenbuhl P, Roux CH, Fardellone P, Le Bihan E. Prevalence of spondyloarthropathies in France: 2001. Ann Rheum Dis. 2005;64(10):1431-5.

37. Boyer GS, Templin DW, Bowler A, Lawrence RC, Heyse SP, Everett DF. Spondyloarthropathy in the community: differences in severity and disease expression in Alaskan Eskimo men and women. J Rheumatol. 2000;27(1):170-6.

38. Buschiazzo E, Maldonado-Cocco JA, Arturi P, Citera G, Berman A, Nitsche A. Epidemiology of spondyloarthritis in Argentina. Am J Med Sci. 2011;341(4):289-92.

39. Olivieri I, D'Angelo S, Padula A, Palazzi C. The challenge of early diagnosis of psoriatic arthritis. J Rheumatol. 2008;35(1):3-5.

40. Alamanos Y, Voulgari PV, Drosos AA. Incidence and prevalence of psoriatic arthritis: a systemic review. J Rheumatol. 2008;35 (7):1354-8.

41. Catanoso M, Pipitone N, Salvarani C. Epidemiology of psoriatic arthritis. Reumatismo. 2012;64(2):66-70.

42. Li R, Sun J, Ren LM, Wang HY, Liu WH, Zhang XW. Epidemiology of eight common rheumatic disease in China: a large-scale cross-sectional survey in Beijing. Rheumatology (Oxford). 2012;51(4):721-9.

43. Cakır N, Pamuk ÖN, Derviș E, Imeryüz N, Uslu H, Benian Ö. The prevalences of some rheumatic diseases in western Turkey: Havsa study. Rheumatol Int. 2012;32(4):895-908.

44. Gladman DD. Psoriatic arthritis. Dermatol Ther. 2004;17(5):350-63.

45. Leonard DG, O'Duffy JD, Rogers RS. Prospective analysis of psoriatic arthritis in patients hospitalized for psoriasis. Mayo Clin Proc. 1978;53(8):511-8.

46. Carneiro JN, Paula AP, Martins GA. Psoriatic arthritis in patients with psoriasis: evaluation of clinical and epidemiological features in 133 patients followed at the University hospital of Brasília. An Bras Dermatol. 2012;87(4):539-44.

47. De Marco G, Cattaneo A, Battafarano N, Lubrano E, Carrera CG, Marchesoni A. Not simply a matter of psoriatic arthritis: epidemiology of rheumatic diseases in psoriatic patients. Arch Dermatol Res. 2012;304(9):719-26.

48. Christophers E, Barker JN, Griffiths CE, Daudén E, Milligan G, Molta C. The risk of psoriatic arthritis remains constant following initial diagnosis of psoriasis among patients seen in European dermatology clinics. J Eur Acad Dermatol Venereol. 2010;24 (5):548-54.

49. - Li W, Han J, Qureshi AA. Smoking and risk of incident psoriatic arthritis in US women. Ann Rheum Dis. 2012;71 (6):804-8. A cohort of 94,874 participants from the Nurses' Health Study II were assessed over 303,970 person-years of follow-up, with data suggesting that smoking is associated with development of PsA. In this study, 157 incident PsA cases were identified. Compared with never smokers, the relative risk (RR) for developing PsA was 1.54 for past smokers (95\% CI 1.062.24) and 3.13 for current smokers (95\% CI 2.08-4.71). With increasing smoking duration or pack-years, the risk of PsA increased monotonically ( $p$ for trend $<0.0001$ ). Of note, this was the largest study to investigate this question.

50. Pattison E, Harrison BJ, Griffiths CE, Silman AJ, Bruce IN. Environmental risk factors for the development of psoriatic arthritis: results from a case-control study. Ann Rheum Dis. 2008;67(5):672-6.

51. • Love T, Zhu Y, Zhang Y, Wall-Burns L, Ogdie A, Gelfand JM. Obesity and the risk of psoriatic arthritis: a population-based study. Ann Rheum Dis. 2012;71(8):1273-7. A cohort of 75,395 individuals with psoriasis from The Health Improvement Network (an electronic medical records database in the UK) was assessed over an average of 5 years of follow-up, and determined that obesity is a risk factor for the development of incident PSA. Compared with psoriasis patients with $B M I<25 \mathrm{~kg} / \mathrm{m}^{2}$, the RRs for developing PSA were 1.09 (0.93-1.28) for BMIs from 25.0 to 25.9, 1.22 (1.02-1.47) for BMIs from 30.0 to 34.9 and 1.48 (1.20-1.81) for BMIs $\geq 35$. This raises the question whether weight reduction may be important to prevent PSA among patients with psoriasis.

52. - Soltani-Arabshahi R, Wong B, Feng BJ, Goldgar DE, Duffin $\mathrm{KC}$, Krueger GG. Obesity in early adulthood as a risk factor for psoriatic arthritis. Arch Dermatol. 2010;146(7):721-6. This study examined the risk factors for developing PSA in a cohort of 943 subjects with dermatologist-diagnosed psoriasis using selfreported questionnaires. They found that BMI at age 18 years was predictive of the development of PSA (odds ratio [OR], 1.06) $(P<0.01)$ over and above control variables.

53. Thumboo J, Uramoto K, Shbeeb MI, O'Fallon WM, Crowson CS, Gibson LE. Risk factors for the development of psoriatic arthritis: a population based nested case control study. J Rheumatol. 2002;29(4):757-62.

54. Setty AR, Curhan G, Choi HK. Smoking and the risk of psoriasis in women: Nurses' health study II. Am J Med. 2007;120(11):953-9.

55. - Eder L, Shanmugarajah S, Thavaneswaran A, Chandran V, Rosen CF, Cook RJ. The association between smoking and the development of psoriatic arthritis among psoriasis patients. Ann Rheum Dis. 2012;71(2):219-24. In this case-control study, a multivariate analysis demonstrated that being a current smoker versus a lifetime nonsmoker was inversely associated with PsA (OR 0.57, $p=0.002)$, whereas past smoker versus lifetime nonsmoker status was not significant, similar to the previous study.

56. • Eder L, Law T, Chandran V, Shanmugarajah S, Shen H, Rosen CF. Association between environmental factors and onset of psoriatic arthritis in patients with psoriasis. Arthritis Care Res (Hoboken). 2011;63(8):1091-7. In this case-control study, the cases were patients with recent-onset PSA $(n=159)$ and controls were psoriasis patients without arthritis $(n=159)$. Smoking was inversely associated with the development of PSA, with an OR of 0.6 (95\% CI 0.36-0.89). It is important to be aware that the role of smoking as a risk factor for PSA is less clear; data show both direct and inverse correlations.

57. Attwa E, Swelam E. Relationship between smoking-induced oxidative stress and the clinical severity of psoriasis. J Eur Acad Dermatol Venereol. 2011;25(7):782-7.

58. Vassalle C, Maffei S, Ndreu R, Mercuri A. Age-related oxidative stress modulation by smoking habit and obesity. Clin Biochem. 2009;42(7-8):739-41.

59. Arnson Y, Shoenfeld Y, Amital H. Effects of tobacco smoke on immunity, inflammation and autoimmunity. J Autoimmun. 2010;34 (3):J258-65.

60. Sopori M. Effects of cigarette smoke on the immune system. Nat Rev Immunol. 2002;2(5):372-7.

61. van Maanen MA, Lebre MC, van der Poll T, LaRosa GJ, Elbaum D, Vervoordeldonk MJ. Stimulation of nicotinic acetylcholine receptors attenuates collagen-induced arthritis in mice. Arthritis Rheum. 2009;60(1):114-22.

62. Ogdie A, Langan S, Love T, Haynes K, Shin D, Seminara N, et al. Prevalence and treatment patterns of psoriatic arthritis in the United Kingdom. Rheumatology (Oxford). 2012. doi:10.1093/ rheumatology/kes324.

63. Gelfand JM, Gladman DD, Mease PJ, Smith N, Margolis DJ, Nijsten T. Epidemiology of psoriatic arthritis in the population of the United States. J Am Acad Dermatol. 2005;53(4):573.

64. • Ash ZR, Tinazzi I, Gallego CC, Kwok C, Wilson C, Goodfield M. Psoriasis patients with nail disease have a greater magnitude of underlying systemic subclinical enthesopathy than those with 
normal nails. Ann Rheum Dis. 2012;71(4):553-6. Forty-six patients with psoriasis (31 with nail disease) and 21 matched healthy controls (HC) were recruited; 804 entheses of upper and lower limbs were scanned using ultrasonography. Enthesopathy scores were significantly higher in patients with nail disease than in patients without nail disease. Nail psoriasis is likely to be an important risk factor for PsA development.

65. Scarpa R, Soscia E, Peluso R, Atteno M, Manguso F, Del Puente A. Nail and distal interphalangeal joint in psoriatic arthritis. $J$ Rheumatol. 2006;33(7):1315-9.

66. Farber EM, Nall L. Natural history and treatment of scalp psoriasis. Cutis. 1992;49(6):396-400.

67. Setty AR, Curhan G, Choi HK. Obesity, waist circumference, weight change, and the risk of psoriasis in women: Nurses' health study II. Arch Intern Med. 2007;167(15):1670-5.

68. Tam LS, Tomlinson B, Chu TT, Li M, Leung YY, Kwok LW. Cardiovascular risk profile of patients with psoriatic arthritis compared to controls-the role of inflammation. Rheumatology (Oxford). 2008;47(5):718-23.

69. Bhole VM, Choi HK, Burns LC, Vera Kellet C, Lacaille DV, Gladman DD. Differences in body mass index among individuals with PsA, psoriasis, RA and the general population. Rheumatology (Oxford). 2012;51(3):552-6.

70. Taylor WJ. Impact of psoriatic arthritis on the patient: through the lens of the WHO international classification of functioning, health, and disability. Curr Rheumatol Rep. 2012;14(4):369-74.

71. Leung YY, Ho KW, Zhu TY, Tam LS, Kun EW, Li EK. Testing scaling assumptions, reliability and validity of medical outcomes study short-form 36 health survey in psoriatic arthritis. Rheumatology (Oxford). 2010;49(8):1495-501.

72. Lementowski PW, Zelicof SB. Obesity and osteoarthritis. Am J Orthop. 2008;37:148-51.

73. Gladman D, Antoni C, Mease P, Clegg D, Nash P. Psoriatic arthritis: epidemiology, clinical features, course and outcome. Ann Rheum Dis. 2005;64(Suppl II):ii14-7.

74. Kane D, Stafford L, Bresnihan B, FitzGerald O. A prospective, clinical and radiological study of early psoriatic arthritis: an early synovitis clinic experience. Rheumatology. 2003;42(12):1460-8.

75. Bond S, Farewell V, Schentag C, et al. Predictors for radiological damage in psoriatic arthritis: results from a single centre. Ann Rheum Dis. 2007;66:370-6.

76. Simon P, Pfoehler C, Bergner R, Schreiber M, Pfreundschuh M, Assmann G. Swollen joint count in psoriatic arthritis is associated with progressive radiological damage in hands and feet. Clin Exp Rheumatol. 2012;30(1):45-50.

77. Cresswell L, Chandran V, Farewell VT, Gladman DD. Inflammation in an individual joint predicts damage to that joint in psoriatic arthritis. Ann Rheum Dis. 2011;70(2):305-8.

78. Gladman DD, Mease PJ, Choy EH, Ritchlin CT, Perdok RJ, Sasso EH. Risk factors for radiographic progression in psoriatic arthritis: subanalysis of the randomized controlled trial ADEPT. Arthritis Res Ther. 2010;12(3):R113.

79. Ibrahim G, Waxman R, Helliwell PS. The prevalence of psoriatic arthritis in people with psoriasis. Arthritis \& Rheumatism. 2009;61(10):1373-8.

80. Gladman D, Thavaneswaran A, Chandran V, Cook R. Do patients with psoriatic arthritis who present early fare better than those presenting later in the disease? Ann Rheum Dis. 2011;70:2152-4.

81. Anderson J, Wells G, Verhoeven A, Felson D. Factors predicting response to treatment in rheumatoid arthritis: the importance of disease duration. Arth Rheum. 20000;43(1):22-9.

82. Lard L, Visser H, Speyer I, Vander Horst-Bruinsma I, Zwinderman A, Breedveld FC, Hazes JM. Early versus delayed treatment in patients with recent-onset rheumatoid arthritis: comparison of two cohorts who received different treatment strategies. Am J Med. 2001;111(6):446-51.
83. Haraoui B, Pope J. Treatment of early rheumatoid arthritis: concepts in management. Semin Arth Rheum. 2011;40:371-88.

84. Breedveld F. The value of early intervention in RA-a window of opportunity. Clin Rheumatol. 2011;30 Suppl 1:S33-9.

85. Gladman DD, Thavaneswaran A, Chandran V, Cook RJ. Do patients with psoriatic arthritis who present early fare better than those presenting later in the disease? Ann Rheum Dis. 2011;70 (12):2152-4.

86. Khraishi M, Landells I, Heale C, Mugford G, Grouchy B. The Psoriasis and Arthritis Screening Questionnaire (PASQ): a sensitive and specific tool to diagnose psoriatic arthritis patients with high correlation to the CASPAR criteria. Presentation 83rd Annual Conference of the Canadian Dermatology Association 2008.

87. Husni ME, Meyer KH, Cohen DS, Mody E, Qureshi AA. The PASE questionnaire: pilot-testing a psoriatic arthritis screening and evaluation tool. J Am Acad Dermatol. 2007;57(4):581-7.

88. Ibrahim GH, Buch MH, Lawson C, Waxman R, Helliwell PS. Evaluation of an existing screening tool for psoriatic arthritis in people with psoriasis and the development of a new instrument: the Psoriasis Epidemiology Screening Tool (PEST) questionnaire. Clin Exp Rheumatol. 2009;27(3):469-74.

89. Dominguez PL, Husni ME, Holt EW, Tyler S, Qureshi AA. Validity, reliability, and sensitivity-to-change properties of the psoriatic arthritis screening and evaluation questionnaire. Arch Dermatol Res. 2009;301(8):573-9.

90. Gladman DD, Schentag CT, Tom BD, Chandran V, Brockbank J, Rosen C. Development and initial validation of a screening questionnaire for psoriatic arthritis: the Toronto Psoriatic Arthritis Screen (ToPAS). Ann Rheum Dis. 2009;68(4):497-501.

91. Khraishi M, Mong J, Landelis I. The electronic Psoriasis and Arthritis Screening Questionnaire (ePASQ): a sensitive and specific tool to diagnose psoriatic arthritis patients. J Cutan Med Surg. 2011;15(3):143-9.

92. Walsh JA, Callis Duffin K, Krueger GG, Clegg DO. Limitations in screening instruments for psoriatic arthritis: a comparison of instruments in patients with psoriasis. J Rheumatol (in press).

93. Klinkhoff A. Rheumatology: 5. Diagnosis and management of inflammatory polyarthritis. CMAJ. 2000;162(13):1833-8.

94. Suresh E. Diagnosis of early rheumatoid arthritis: what the nonspecialist needs to know. J R Soc Med. 2004;97:421-4.

95. Mease PJ. Inflammatory musculoskeletal disease: identification and assessment. J Rheumatol. 2011;38:557-61.

96. The Group for Research and Assessment of Psoriasis and Psoriatic Arthritis (GRAPPA) Home Page. 2012(Dec 3). http:// www.grappanetwork.org/.

97. Salliot C, Dernis E, Lavie F, et al. Diagnosis of peripheral psoriatic arthritis: recommendations for clinical practice based on data from the literature and experts opinion. Joint Bone Spine. 2009;76(5):532-9.

98. Ory P, Gladman D, Mease P. Psoriatic arthritis and imaging. Ann Rheum Dis. 2005;64(Suppl II):ii55-7.

99. Gutierrez M, Filippucci E, De Angelis R, Filosa G, Kane D, Grassi W. A sonographic spectrum of psoriatic arthritis: "the five targets". Clin Rheumatol. 2010;29:133-42.

100. McQueen F, Dalbeth N, Doyle A. MRI in psoriatic arthritis: insights into pathogenesis and treatment response. Curr Rheumatol Rep. 2008;10:303-10.

101. Ritchlin C, Kavanaugh A, Gladman DD, et al. Treatment recommendations for psoriatic arthritis. Ann Rheum Dis. 2009;68:1387-94.

102. Tillett W, McHugh N. Treatment algorithms for early psoriatic arthritis: do they depend on disease phenotypes? Curr Rheumatol Rep. 2012;14(4):334-42.

103. Ash Z, Gaujoux-Viala C, Gossec L, et al. A systematic literature review of drug therapies for treatment of psoriatic arthritis: current evidence and meta-analysis informing the EULAR 
recommendations for the management of psoriatic arthritis. Ann Rheum Dis. 2012;71(3):319-26.

104. Gossec L, Smolen JS, Gaujoux-Viala C, Ash Z, et al. European League Against Rheumatism recommendations for the management of psoriatic arthritis with pharmacological therapies. Ann Rheum Dis. 2012;71(1):4-12.

105. Kingsley GH, Kowalczky A, Taylor H, et al. A randomized placebo-controlled trial of methotrexate in psoriatic arthritis. Rheumatology (Oxford). 2012;51(8):1368-77.

106. Mease PJ. Spondylarthritis: Is methotrexate effective in psoriatic arthritis? Nat Rev Rheumatol. 2012;8(5):251-2.

107. Han C, Robinson Jr DW, Hackett MV, Paramore LC, Fraeman $\mathrm{KH}$, Bala MV. Cardiovascular disease and risk factors in patients with rheumatoid arthritis, psoriatic arthritis, and ankylosing spondylitis. J Rheumatol. 2006;33(11):2167-72.

108. Peters MJ, van der Horst-Bruinsma IE, Dijkmans BA, Nurmohamed MT. Cardiovascular risk profile of patients with spondylarthropathies, particularly ankylosing spondylitis and psoriatic arthritis. Semin Arthritis Rheum. 2004;34(3):585-92.

109. Kimhi O, Caspi D, Bornstein NM, Maharshak N, Gur A, Arbel Y. Prevalence and risk factors of atherosclerosis in patients with psoriatic arthritis. Semin Arthritis Rheum. 2007;36(4):203-9.
110. Mok CC, Kwok CL, Ho LY, Chan PT, Yip SF. Life expectancy, standardized mortality ratios, and causes of death in six rheumatic diseases in Hong Kong, China. Arthritis Rheum. 2011;63 (5):1182-9.

111. McHugh NJ, Arumugam R. Mortality and cause of death in psoraitic arthritis. J Rheumatol Suppl. 2012;89:32-5.

112. Dubreuli M, Rho YH, Man A, et al. The risk of diabetes in psoriatic arthritis and rheumatoid arthritis. Arthritis Rheum. 2012;64(S10):S1107.

113. •• Li WQ, Han JL, Manson JE, Rimm EB, Rexrode KM, Curhan GC. Psoriasis and risk of nonfatal cardiovascular disease in U.S. women: a cohort study. Br J Dermatol. 2012;166(4):811-8. This study examined the association between PSA and CVD in a large cohort of U.S. women from the Nurses' Health Study II $(n=96,008)$. They found a significantly elevated risk of nonfatal CVD, particularly MI, in women with PSA, even after adjusting for traditional cardiovascular risk factors. Adjusted hazard ratios (95\% CI) for nonfatal CVD, nonfatal MI, and nonfatal stroke were 5.32 (2.859.94), 7.4 (3.5-15.66), and 3.18 (1.02-9.91) respectively.

114. Khraishi M, MacDonald D, Rampakakis E, Vaillancourt J, Sampalis JS. Prevalence of patient-reported comorbidities in early and established psoriatic arthritis cohorts. Clin Rheumatol. 2011;30 (7):877-85. 